\title{
Columnar Specificity of Intrinsic Horizontal and Corticocortical Connections in Cat Visual Cortex
}

\author{
Charles D. Gilbert and Torsten N. Wiesel \\ The Rockefeller University, New York, New York 10021
}

\begin{abstract}
A prominent and stereotypical feature of cortical circuitry in the striate cortex is a plexus of long-range horizontal connections, running for 6-8 $\mathrm{mm}$ parallel to the cortical surface, which has a clustered distribution. This is seen for both intrinsic cortical connections within a particular cortical area and the convergent and divergent connections running between area 17 and other cortical areas. To determine if these connections are related to the columnar functional architecture of cortex, we combined labeling of the horizontal connections by retrograde transport of rhodamine-filled latex microspheres (beads) and labeling of the orientation columns by 2-deoxyglucose autoradiography. We first mapped the distribution of orientation columns in a small region of area 17 or 18 , then made a small injection of beads into the center of an orientation column of defined specificity, and after allowing for retrograde transport, labeled vertical orientation columns with the 2-deoxyglucose technique. The retrogradely labeled cells were confined to regions of orientation specificity similar to that of the injection site, indicating that the horizontal connections run between columns of similar orientation specificity. This relationship was demonstrated for both the intrinsic horizontal and corticocortical connections. The extent of the horizontal connections, which allows single cells to integrate information over larger parts of the visual field than that covered by their receptive fields, and the functional specificity of the connections, suggests possible roles for these connections in visual processing.
\end{abstract}

The cerebral cortex has a modular structure consisting of repeating sets of functional columns. This organization has been determined in particular detail in the primary visual cortex, which is organized retinotopically and, on a finer scale, has sets of columns of cells sharing the same orientation preference and ocular dominance (Hubel and Wiesel, 1962, 1977). Consequently, in order not to disrupt cortical columnar and retinotopic organization, it seemed entirely logical that the cortical connectivity would be fairly restricted in its extent along planes parallel to the cortical surface, with most of the connections running across the cortical layers, perpendicular to the cortical surface. The patterns of cortical connectivity revealed by Golgi studies were consistent with this view (Ramón y Cajal, 1922;

\footnotetext{
Received Aug. 8, 1988; revised Oct. 25, 1988; accepted Oct. 26, 1988.

This work was supported by NSF Grants BNS 8351738 and BNS 8615935 and NIH Grant EY05253; C.G. was supported by awards from the Weil-Caulier and Rita Allen Foundations. We wish to thank Pat Rivlin and Pamela Joyce for their superb technical assistance and Peter Pierce for photography.

Correspondence should be addressed to Charles D. Gilbert, M.D., Ph.D., The Rockefeller University, 1230 York Avenue, New York, NY 10021.

Copyright (C) 1989 Society for Neuroscience $0270-6474 / 89 / 072432-11 \$ 02.00 / 0$
}

O'Leary, 1941; Lorente de No, 1949; Lund and Boothe, 1975). This rather comfortable agreement between anatomy and physiology was disrupted by the discovery that cortical connections instead run for many millimeters parallel to the cortical surface, in seeming violation of the principles of receptive field size and functional architecture (Fisken et al., 1975; Gilbert and Wiesel, 1979, 1983). An intriguing pattern of these connections, revealed by intracellular HRP injections, was that axon collaterals of individual pyramidal cells were distributed in discrete clusters, spaced from 0.5 to $1 \mathrm{~mm}$ apart (Gilbert and Wiesel, 1979, 1983; Martin and Whitteridge, 1984). Extracellular HRP injections showed that the horizontal connections were convergent as well as divergent and that cells projecting to the injection site were distributed in a lattice-like pattern (Rockland and Lund, 1982, 1983). Taken together, these experiments suggested that horizontal connections might respect the periodicity of the cortical columns (Gilbert and Wiesel, 1979; Mitchison and Crick, 1982).

Very similar patterns of clustered long-range connections have been observed not only with respect to the intrinsic connections of a given cortical area but also in the connections between different cortical areas. This had originally been seen with extracellular HRP injections, where a focal injection of HRP in one area, followed by retrograde transport of the label to the antecedent area, resulted in a large region of labeled cells. Within this region the cells were distributed in discrete clusters (Gilbert and Kelly, 1975; Wong-Riley, 1979; Montero, 1980; Gilbert and Wiesel, 1981a, b; Tigges et al., 1981; Maunsell and Van Essen, 1983; Bullier et al., 1984). This pattern is seen not only in the projections between visual cortical areas, but also in regions serving other sensory modalities and in frontal cortex as well (Goldman and Nauta, 1977; Imig and Brugge, 1978; Jones et al., 1978; Imig and Reale, 1981; Goldman-Rakic and Schwartz, 1982). In primary visual cortex, the corticocortical projection clusters, when projected onto the cortical surface, form a pattern of branching stripes, similar to the pattern of orientation columns observed with 2-deoxyglucose autoradiography, once again suggesting a relationship between the clustering pattern and the cortical columnar structure (Gilbert and Wiesel, 1981a).

In the current study we show that the long-range horizontal connections connect columns of similar orientation specificity. We propose that it is from this relationship that this pattern of connections derives its functional role.

\section{Materials and Methods}

Intrinsic cortical connections and corticocortical connections were labeled in cat visual cortex by means of a fluorescent retrograde tracer, and orientation columns were visualized by 2 -deoxyglucose autoradiography. 


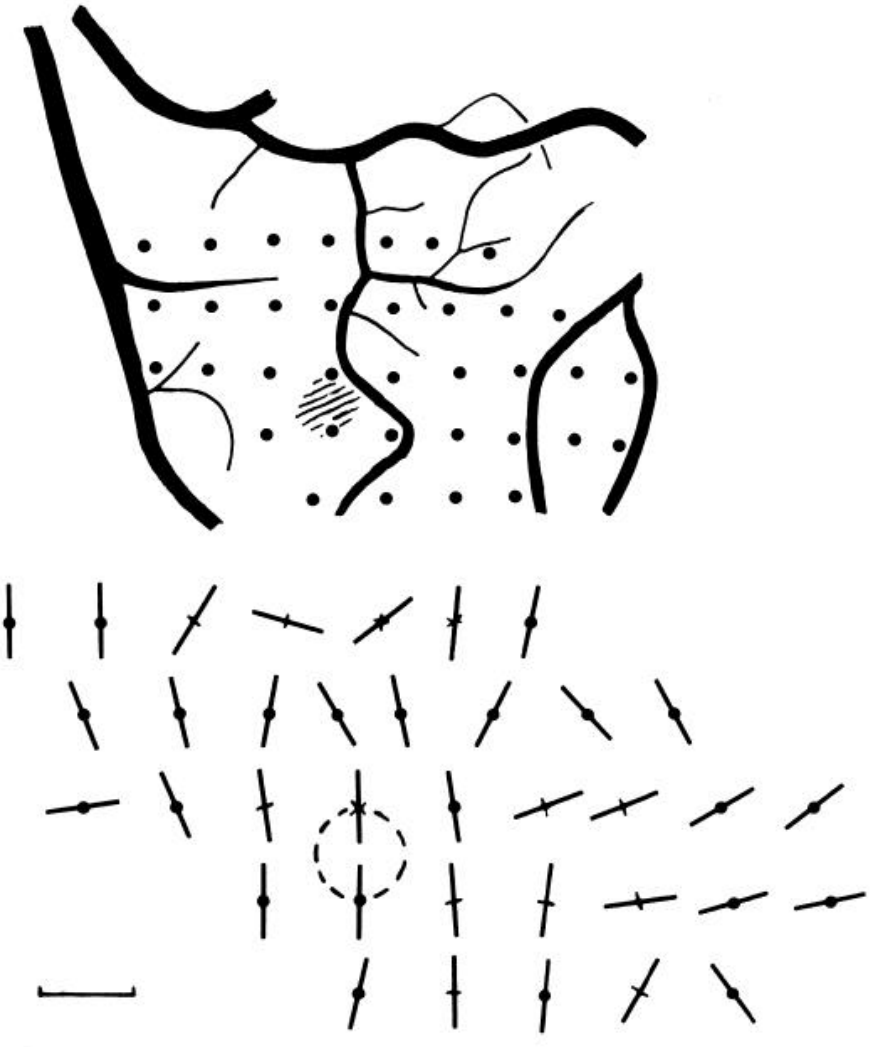

Figure 1. Experimental design. Top, The vascular pattern on a region of the dorsal surface of the postlateral gyrus of the cat, where one finds striate cortex, the $17 / 18$ border being located a few millimeters lateral. In other experiments, where injections were placed in area 18, a more anterior part of the lateral gyrus was exposed, over a region where 18 lies on the surface of the gyrus. A series of electrode penetrations (indicated by the dots), spaced approximately $150 \mu \mathrm{m}$ apart, were made sequentially, using both the vasculature and the coordinates of the micromanipulator as references. The placement and size of the injection site are indicated by the cross-hatched area. Bottom, Orientation preferences of the cells encountered at each of the penetrations. Ocular dominance is indicated by dots (contralateral dominance), lines (ipsilateral) and $\times$ 's (equal response to stimulation of either eye). Note that in this region there is a relatively large area where cells have close to vertical orientation preference, and over a short distance the orientation changes quickly to another large area of horizontal orientation preference. The injection, as indicated by the dashed circle, was placed centrally in the area of vertical orientation preference. Scale bar, $150 \mu \mathrm{m}$.

A total of 14 injections was made in 8 adult cats. In separate experiments, we labeled the intrinsic cortical connections in area 17 (6 injections) and the cells projecting from area 17 to area 18 ( 8 injections). Adult cats were used for this study. The animals were initially anesthetized with ketamine $\mathrm{HCl}(10 \mathrm{mg} / \mathrm{kg})$. After venous cannulation, the cats were injected with $\mathrm{Na}$ thiopental $(10-20 \mathrm{mg} / \mathrm{kg})$. The trachea was catheterized, and the animal was paralyzed with succinylcholine (15 $\mathrm{mg} / \mathrm{kg} / \mathrm{hr}$ ) and placed on a respirator. The respiratory rate and volume were adjusted for an end-tidal $\mathrm{CO}_{2}$ partial pressure of $30-35 \mathrm{~mm} \mathrm{Hg}$. The animal's ECG, EEG, and temperature were monitored continuously. Using sterile surgical technique, a hole was drilled in the skull over the surface of the postlateral or lateral gyri, in order to place injections in areas 17 or 18 .

The tracer used in this study is rhodamine-filled latex microspheres (Lumafluor, Katz et al., 1984). The advantage of the beads is that one can make a very small injection, approximately $200 \mu \mathrm{m}$ across (for a $0.25 \mu \mathrm{l}$ injection), and they do not readily diffuse from the injection site. To place the injection in a particular orientation column, as far as possible from columns of differing orientations, we first mapped a patch of cortex by multiple electrode penetrations. An example of this is shown

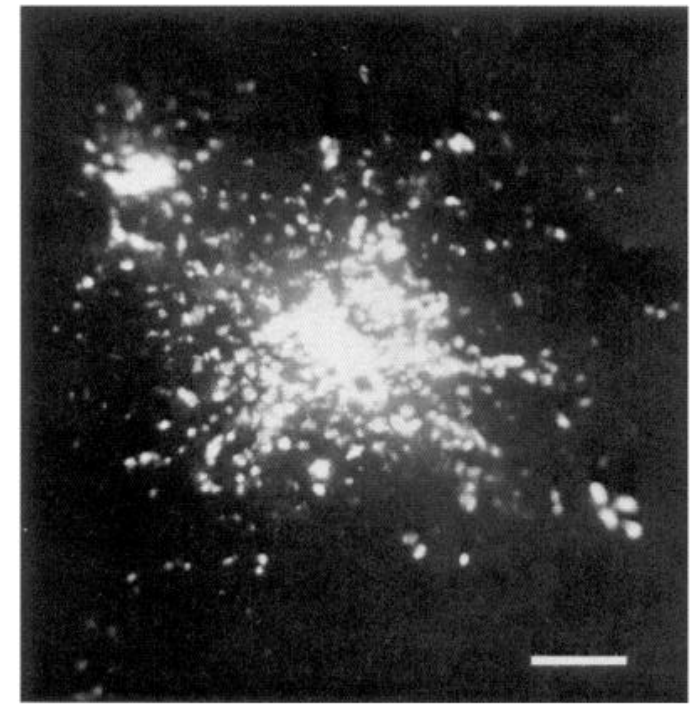

Figure 2. Bead injection site, seen in a tangential section through the superficial cortical layers. The volume of the injection was approximately $0.25 \mu \mathrm{l}$, resulting in an injection with diameter of $200 \mu \mathrm{m}$. Scale bar, $100 \mu \mathrm{m}$.

in Figure 1, which shows the placement of an injection in area 17. The upper part of the figure is a sketch of the vascular pattern and the location of the electrode penetrations relative to particular blood vessels. The lower part shows, at slightly larger magnification, the distribution of the orientation columns in this map. Notice that rather than being distributed in stripes of uniform thickness, one sees vertically oriented cells congregated into large domains, with a shift over a relatively short distance to another domain of horizontally oriented cells. In other regions, cells of a particular orientation formed narrower bands. In this experiment the size and position of the injection site are shown by the dotted line in the lower part of the figure and the shading in the upper part.

The injections are made with a glass micropipette (tip diameter, 25 $\mu \mathrm{m})$ at a depth of approximately $500-600 \mu \mathrm{m}$, corresponding to the layer $3 / 4$ border. The injection tends to track along the pipette and thus extends throughout the superficial cortical layers. An example of an injection site, shown in surface view, indicating the scale and shape of the injection, is shown in Figure 2. This is the injection corresponding to the experiment shown in Figure 5, D-F. The wound is sutured; the cat is given an injection of penicillin (Dual-Pen, $0.5 \mathrm{cc}$ ) and is then allowed to recover from anesthesia. The second part of the experiment is done several days later to allow transport of the label. We then label the vertical orientation columns by ${ }^{14} \mathrm{C}$-2-deoxyglucose autoradiography, where the animal views a pattern of vertical stripes of varying thickness while receiving ${ }^{14} \mathrm{C}$-2-deoxyglucose (Sigma) in 5 equal doses at $5 \mathrm{~min}$ intervals $(20 \mu \mathrm{Ci}$ in $0.2 \mathrm{ml} 0.9 \%$ saline followed by $1 \mathrm{ml}$ saline flush). The final dose is given at $20 \mathrm{~min}$, for a total dosage of $100 \mu \mathrm{Ci}$, and the visual stimulation continues for an additional $25 \mathrm{~min}$.

The animal is then perfused with formaldehyde fixative $(4 \% \mathrm{HCHO}$ in $0.1 \mathrm{M} \mathrm{Na}$ phosphate buffer, $\mathrm{pH} 7.4$ ), the relevant block of brain is removed, unfolded, flattened (Olavarria and Van Sluyters, 1985; Tootell and Silverman, 1985), and quick-frozen on a block of brass cooled in dry ice. The cortex is sectioned in a plane tangential to the surface, with sections of $30 \mu \mathrm{m}$ thickness mounted on gelatinized coverslips. The coverslips are mounted in an X-ray cassette on X-ray film (Kodak SB 5 ), and the film is exposed at $-80^{\circ} \mathrm{C}$ for $2-3$ weeks (the intensity of fluorescent staining is maintained by storage at low temperatures) and then developed at the end of this period.

The distribution of labeled cells was mapped with a Zeiss fluorescence microscope equipped with a drawing tube. We included various landmarks such as large blood vessels, cracks in the section and section boundaries in order to align the reconstruction with the autoradiograph. Importantly, the pattern of cell labeling and 2-deoxyglucose labeling was determined for the same sections, allowing for more accurate alignment than is possible when aligning patterns from alternate sections. 


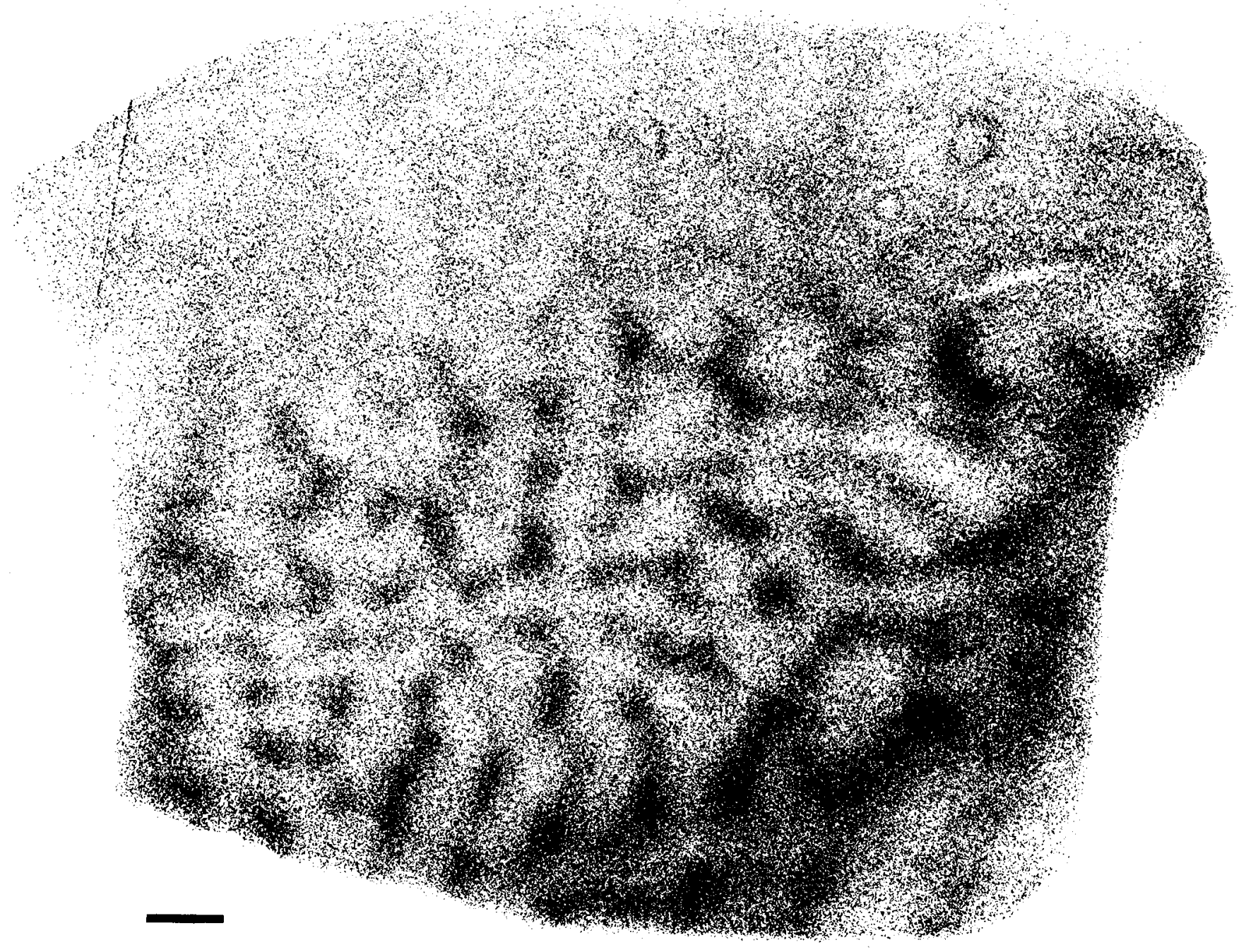

Figure 3. Example of labeling of orientation columns seen in a tangential section taken from flattened cortex. The visual stimulus given during an infusion of 2-deoxyglucose was a large field of vertical lines, varying in thickness and spacing (see Materials and Methods). This section is taken from superficial layers of the cat's visual cortex. Note in the upper (dorsolateral) part of the figure, which corresponds to area 18, the pattern labeling is coarser and fainter than in the lower part (area 17). The pattern of labeling in area 17 consists of dark patchy regions connected by fainter and thinner bands of label.

\section{Results}

Injections were made in area 17 to visualize horizontal intrinsic connections within area 17 and in area 18 to visualize cells in area 17 that project to area 18 . The injection sites were limited to a diameter of $200 \mu \mathrm{m}$, allowing us to restrict the injection to columns spanning a narrow range of orientations. Flattening of the cortex followed by sectioning tangential to the cortical surface enabled us to look at the distribution of orientation columns and cell labeling patterns within a particular layer (Fig. 2). All sections shown are from layer $2+3$, which are the principal source of corticocortical projections and are also heavily labeled in the intrinsic cortical projection experiments. The pattern of labeling of orientation columns is shown in Figure 3. In this experiment, and in all other experiments, the stimulus was a pattern of vertical lines of varying thickness $\left(1 / 8^{\circ}-2^{\circ}\right.$ on a panel covering a visual field area of $60^{\circ} \times 60^{\circ}$ moving with varying velocity in the horizontal direction). Note that the cortical la- beling consisted of a pattern of branching bands that had a patchy appearance, similar to that reported earlier (Lowell et al., 1987). This pattern of labeling is reminiscent of the distribution of orientation columns seen with the maps made with multiple electrode penetrations. At times, cells having a particular orientation specificity were found over a relatively large area (cf. Fig. 1, approximately $500 \mu \mathrm{m}$ in diameter), with a quick shift to areas having orthogonal orientation specificity. In other regions, cells with common orientation preference were grouped together in parallel narrow stripes, with gradual shifts in orientation in directions perpendicular to the stripes. These 2 patterns could correspond to the darkly labeled patches and fainter narrow interconnecting strips seen with the 2-deoxyglucose technique.

The injections of rhodamine-filled latex beads resulted in labeling of large regions of cortex, $6-8 \mathrm{~mm}$ in diameter. A photomicrograph of a field of labeled cells, located in layer $2+3$ approximately $2 \mathrm{~mm}$ away from the injection site in area 17 , 


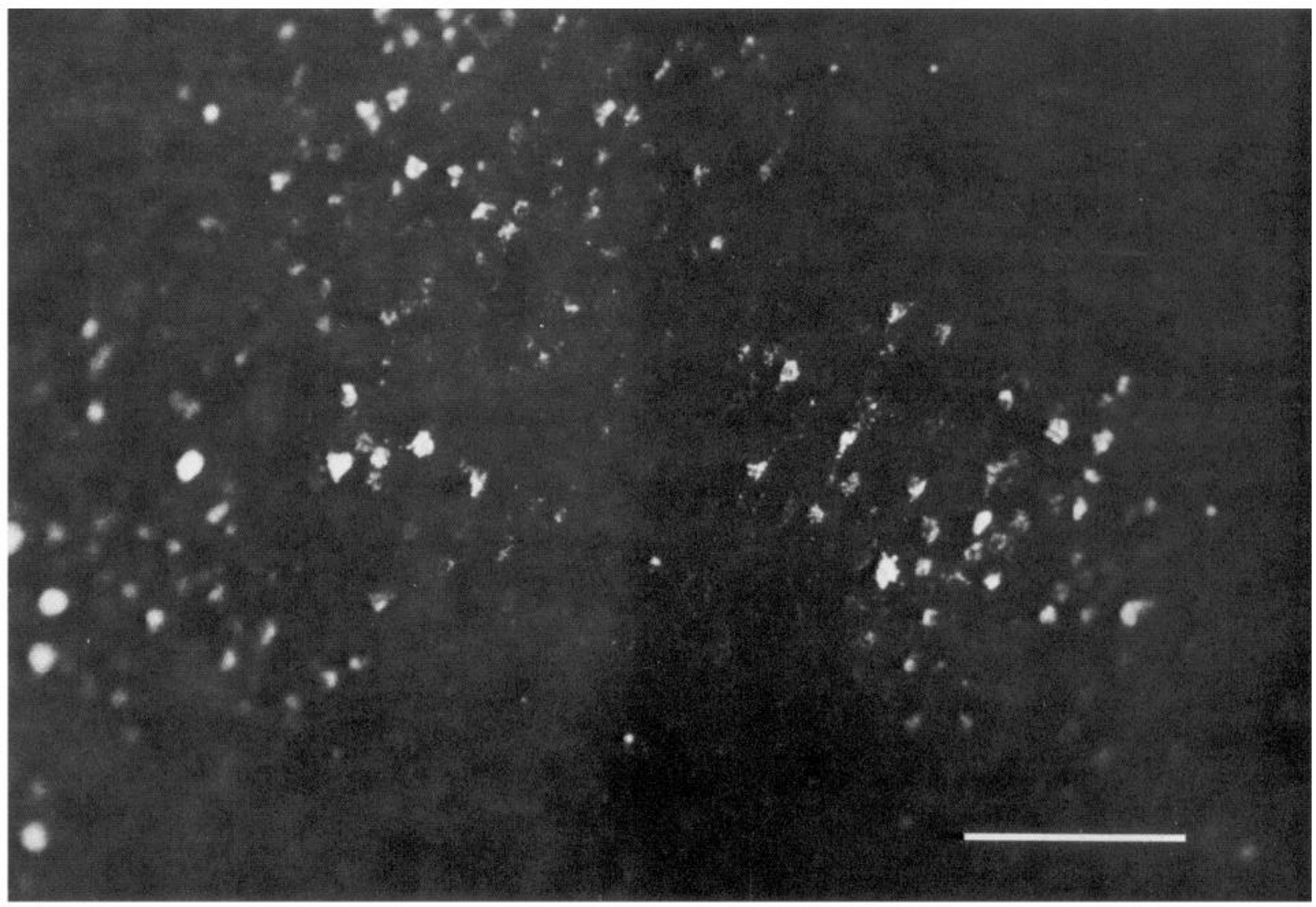

Figure 4. A region of cells retrogradely labeled with the rhodamine-filled latex microspheres (beads) in a tangential section of area 17. The injection site, also in area 17, was located a few millimeters away. In this area one can discern 3 patches of labeled cells. The labeling pattern is constant through the thickness of cortex and could be followed across consecutive tangential sections. Scale bar, $250 \mu \mathrm{m}$.

is shown in Figure 4. The labeled cells are distributed in several clusters of variable size and shape, with at least 30 labeled cells in each (since these are $30 \mu \mathrm{m}$ sections, the total number of cells in a cluster would be considerably greater).

The results from one experiment are shown in Figure 5, $A-$ $C$. The pattern of deoxyglucose labeling in the vicinity of the injection site, in one section, is given in Figure $5 A$. The bead injection was made in a vertical orientation column; the distribution of bead-labeled cells is shown in Figure $5 B$. Note that the labeled region is quite large, $8 \mathrm{~mm}$ in diameter, and within the labeled region the cells have a characteristic clustered distribution. The labeled cells extend for a longer distance along the anteroposterior cortical axis than along the dorsomedial axis. By referring to visuotopic maps of area 17 (Tusa et al., 1978), one can determine the area of visual field corresponding to the labeled cortical region. At this point in the visual field (elevation of $-10^{\circ}$, near the vertical meridian), the labeled cortical area represents an area of visual field of approximately $10^{\circ}$ diameter. In contrast, the receptive field diameter of cells in the superficial layers of cortex in the labeled region run from $1 / 2^{\circ}$ to $2^{\circ}$ in diameter. Another experiment, in which the labeling pattern after bead injection in area 17 is compared with the distribution of orientation columns in the same region, is shown in Figure 5, $D-F$.

The pattern of 2-deoxyglucose labeling can be compared directly with the distribution of labeled cells by superimposing
Figure 5, $A$ and $B$, as seen in $C$, and $D$ and $E$, as shown in $F$. The labeled cells fell consistently over the more darkly deoxyglucose-labeled regions, including some of the "beaded" areas, as well as the interconnecting segments. The most lightly labeled areas were devoid of labeled cells. Clearly, however, while beadlabeled cells were found only over deoxyglucose-labeled vertical orientation columns, there were many darkly labeled regions that had no labeled cells within them. Thus, matched orientation preference was a necessary but not sufficient condition for the correspondence of horizontal connections with cortical columns.

The distribution of corticocortical projection bands seen in area 17 after a bead injection in area 18 is shown in Figure 6. Here, too, we first mapped the distribution of orientation columns in the vicinity of the injection site and selected a vertical orientation column in which to make the injection. We then looked in area 17 at the distribution of labeled cells (Fig. $6 \mathrm{~B}$ ) and the labeled vertical orientation columns (Fig. $6 \mathrm{~A}$ ). The area of bead-labeled cells, as with the intrinsic connections in area 17 , covered a large area, $6 \mathrm{~mm}$ along the long axis of the field of labeled cells; the area was long and narrow and the cells distributed in discrete bands. Like the 2-deoxyglucose labeling, the labeled cortical projection bands had a beaded appearance. When the 2 labeling patterns were superimposed (Fig. $6 \mathrm{C}$ ), we once again found that the labeled cells lay over labeled vertical orientation columns. 

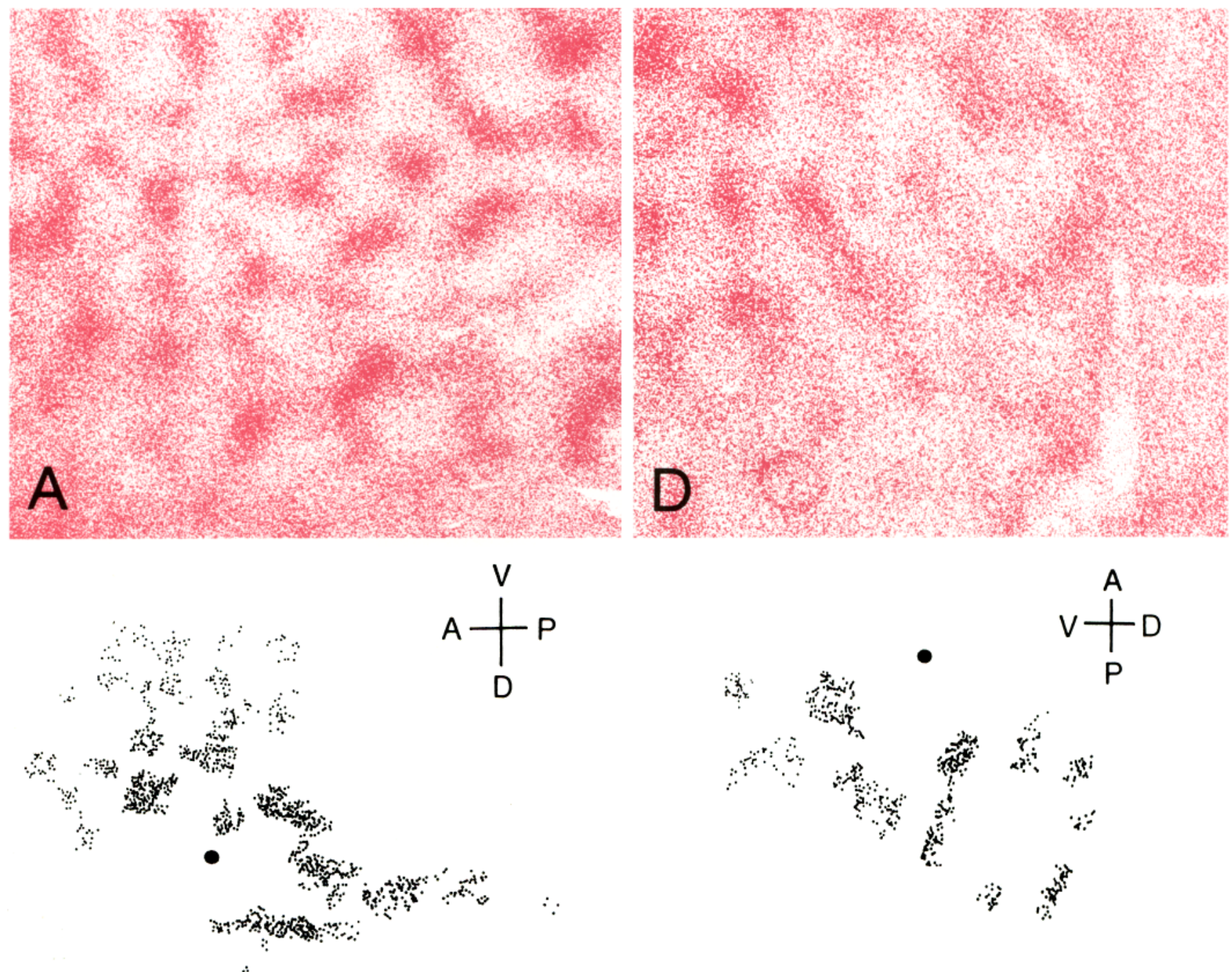

B
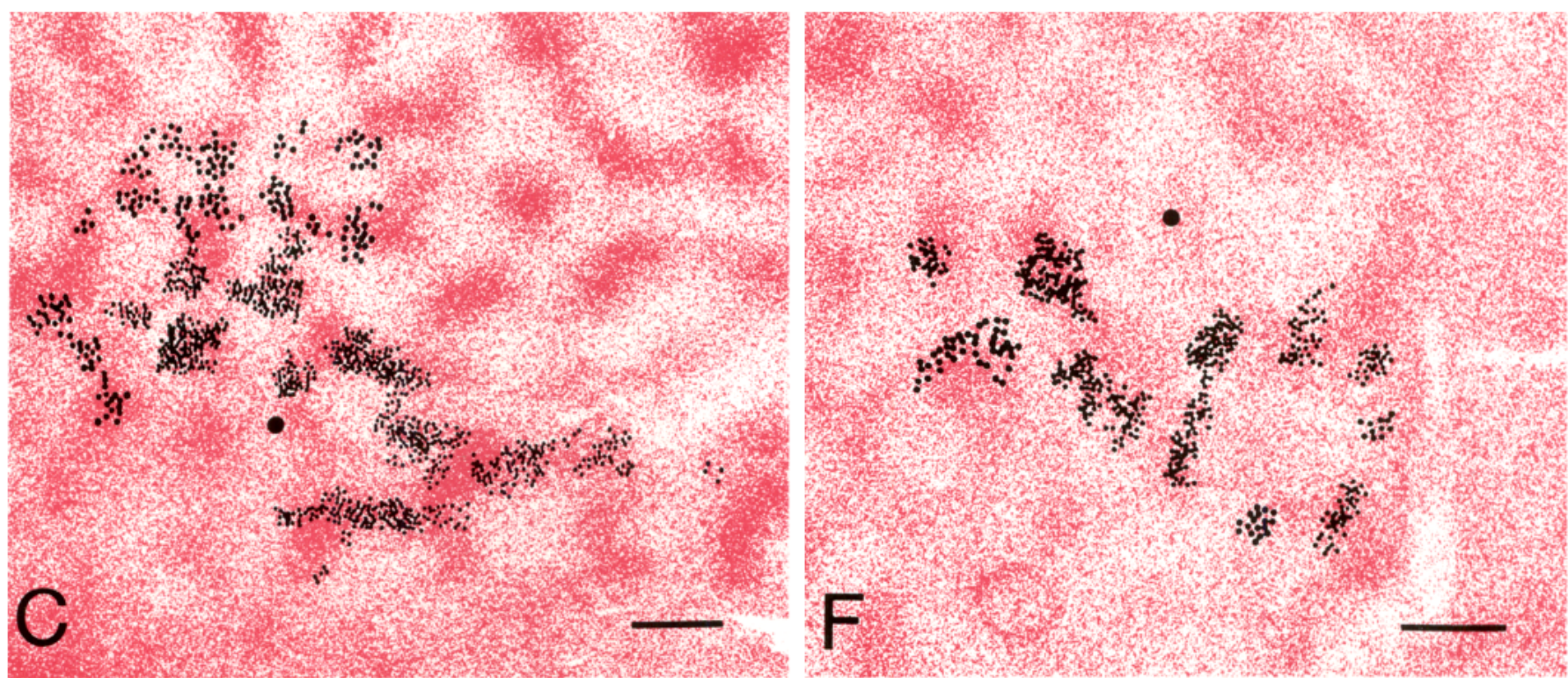
In another experiment labeling corticocortical connections, we injected a horizontal orientation column in area 18 with beads and labeled vertical orientation columns with the deoxyglucose technique. The results from the experiment are shown in Figure 7. In the region of cell labeling, the labeled vertical orientation columns ran in parallel bands (Fig. 7, $A, B$ ). The labeled cells were grouped into a similar looking set of parallel bands (Fig. $7 \mathrm{C}$ ), running along the same axis, but these bands alternated with the deoxyglucose-labeled bands (Fig. 7D). Since the injection was made in a horizontal orientation column in area 18 , these results would imply a projection from horizontal orientation columns in area 17 to horizontal orientation columns in area 18.

With respect to the intrinsic long-range clustered horizontal connections, we were able to obtain bead and deoxyglucose labeling in 6 experiments. In all of these experiments, the patterns of labeling were in register, with connections between columns of similar orientation specificity. With respect to the corticocortical connections, we had the required quality of labeling in 8 experiments, and in all of these experiments the patterns of labeling were in register, showing a "like-to-like" pattern of connections similar to that seen with the intrinsic connections. None of the area 17 or area 18 injections showed the opposite pattern of registration-connections between columns of opposite orientation specificity.

\section{Discussion}

Our results support a rule that is applicable to both intrinsic and corticocortical connections: long-range clustered connections relate columns of similar functional specificity. This relationship was originally suspected on the basis of intracellular injections: Cells intracellularly labeled with HRP often had projections in 2 different layers, and the clusters in the upper tier lay directly over the clusters in the lower tier, suggesting a relationship between the clustering phenomenon and the cortical columns (Gilbert and Wiesel, 1979, 1983). Additional evidence for specificity in column-to-column connectivity was obtained from cross-correlation analysis, a statistical technique based on firing patterns that identifies cells that are interconnected or that share common inputs. Using this approach, Ts'o et al. (1986) found that strong correlated firing was seen only when the orientations of the cell pairs were within $30^{\circ}$ of each other. Notably, a number of the cell pairs with matched orientation preferences did not show correlated firing, because other factors, such as ocular dominance or direction preference, also played a role in determining whether the 2 cells had correlated firing and were thus interconnected. The findings presented here are consistent with the earlier study in that matched orientation preference was a necessary but not sufficient condition for the correspondence of cell labeling with deoxyglucose labeling. In view of the gaps in cell labeling over orientation columns of a given specificity, it is interesting to note that when one makes large injections of tracer into area 18 , one still sees a clustered pattern of labeling in area 17 (Ferrer et al., 1988).

These findings are reminiscent of patterns of connections in the monkey's visual cortex. There, the cells with color and orientation specificity reside in separate compartments, the blobs and interblobs, which are made manifest by the cytochrome oxidase stain. The horizontal connections respect the boundaries of these compartments, with blobs connected to blobs and interblobs connected to interblobs (Livingstone and Hubel, 1984 b). Both cross-correlation and anatomical studies show a specificity at a more detailed level, with connections between orientation columns of similar specificity and between blobs of similar color-opponency (Ts'o and Gilbert, 1988). The connections between $\mathrm{V} 1$ and $\mathrm{V} 2$ are comparable, with blobs in V1 projecting to thin cytochrome oxidase stripes in V2 and interblobs projecting to interstripes (Livingstone and Hubel, 1984a). Thus, whether one is dealing with the submodalities of form and color or the specific columns within these modalities, the orientation columns and color-opponency specific blobs, the connections run between compartments of like specificity. If there is to be communication between compartments, it is more likely to be mediated by connections between the edges of compartments rather than between the center of one compartment and the center of a compartment of opposite specificity. For example, at the boundaries between blobs and interblobs one finds color-specific oriented cells that receive input from colorspecific unoriented cells within the blobs (Ts'o et al., 1987).

The advantage of the technique used in the current study is that one can visualize the orientation columns and horizontal connections in the same section, after processing, so one does not have to worry about section alignment or differential shrinkage produced by perfusion or histological processing. Moreover, the small injection size afforded by the beads allows one to restrict the injection to a narrow range of orientation columns. We utilized the fact that, in cat, deoxyglucose autoradiography is an effective method for localizing orientation columns (Schoppmann and Stryker, 1981). Unfortunately, the deoxyglucose labeling in area 18 was inadequate for us to explore the intrinsic connections within area 18 or the recurrent projection from area 18 to area 17 . There is an apparent discrepancy between our results and those of Matsubara et al. (1987), who found that in area 18 the horizontal connections tended to in

\footnotetext{
Figure 5. Combined deoxyglucose and bead labeling in 2 experiments, both from injections in area 17, to visualize horizontal connections intrinsic to area 17. The deoxyglucose label is shown in red in order to distinguish it from the bead-labeled cells, which are indicated by black dots. The bead and deoxyglucose labeling are seen in the same sections. $A$, Deoxyglucose label, area 17 , after stimulation with pattern of vertical stripes. $B$, Reconstruction of distribution of retrogradely filled bead-labeled cells in same region as that shown in $A$, after injection of beads into a vertical orientation column in area 17. Injection site is indicated by filled black circle, labeled cells by dots. The extent of bead labcling runs 8 mm from end to end (horizontal is along the anteroposterior cortical axis). The cortical axes are indicated in the upper right hand corner. $C$, Superimposition of $A$ and $B$. The clusters of labeled cells lay directly over the deoxyglucose-labeled areas, including both the dark patches and the labeled interconnecting strips of intermediate density. None of the areas of lightest deoxyglucose label contained clusters of labeled cells. The visuotopic location of the injection site was $11^{\circ}$ below the horizontal meridian and $2^{\circ}$ from the vertical meridian into the contralateral visual field. Scale bar, $1 \mathrm{~mm}$. $D$, Deoxyglucose label in area 17 , as in $A$, after stimulation with pattern of vertical stripes. $E$, Reconstruction of retrogradely filled bead-labeled cells in same region of area 17 as that shown in $D$, after injection of beads into a vertical orientation column in area $17 . F$, Superimposition of $D$ and $E$. As with the intrinsic connections, the clusters of labeled cells are in register with the areas of deoxyglucose label, the light intervening areas being devoid of labeled cells. The visuotopic location of the injection site was $1^{\circ}$ below the horizontal meridian and $2^{\circ}$ from the vertical meridian into the contralateral field. Scale bar, $1 \mathrm{~mm}$. Some of the dots in $C$ and $F$ were enlarged to make the cell positions easier to see against the background.
} 


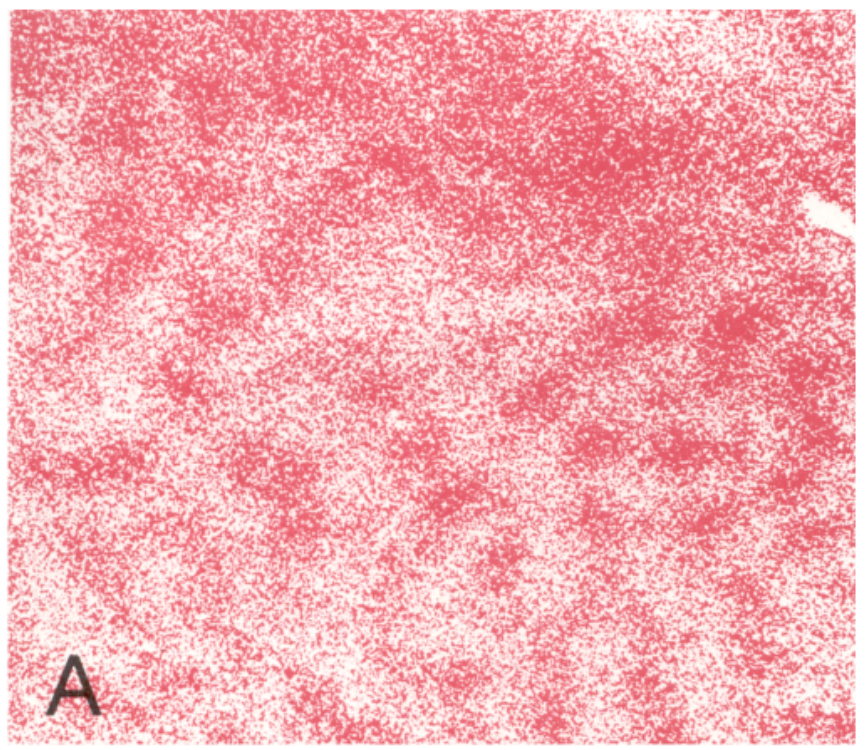

$\left.P\right|_{V} ^{D} A$
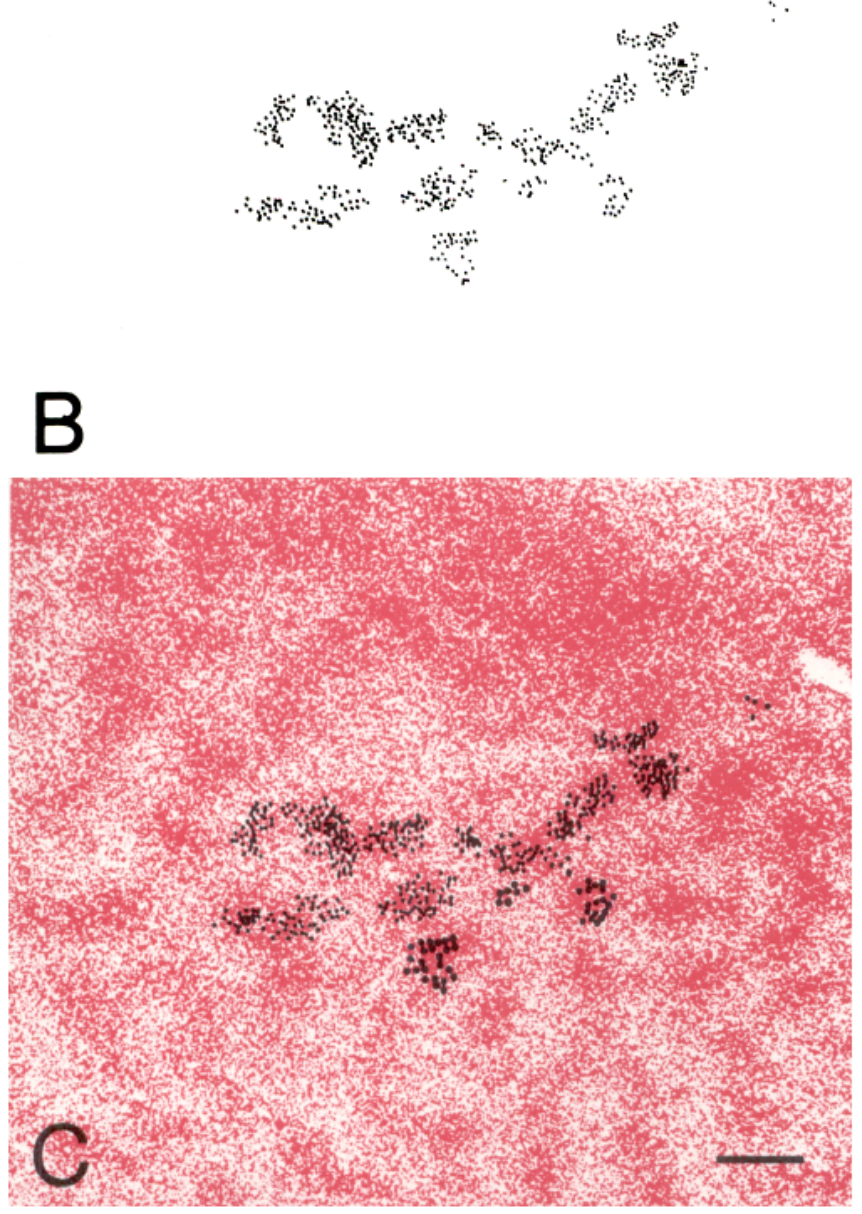

Figure 6. An injection in area 18 to visualize the 17-to-18 cortical projection bands. $A$, Deoxyglucose label, area 17 , after stimulation with pattern of vertical stripes. $B$, Reconstruction of distribution of retro- terconnect columns of orthogonal orientation specificity. It is possible that the discrepancy represents a difference between areas 17 and 18. Alternatively, because of differential shrinkage during histological processing, it may not be easy to compare an orientation map obtained with recordings made prior to perfusion with a projection pattern seen after processing. There is also the danger that the relatively large injections may encompass orientation columns of different specificities. Even so, though on average the projections seen in that study were between columns of different orientation specificity, some of the projections were between columns of similar orientation specificity. Ultimately, the picture will become clearer as new techniques are developed for visualizing orientation columns and projection patterns.

The deoxyglucose labeling that results from binocular stimuli of a single orientation has a characteristic patchy or beaded appearance (Lowell et al., 1987). A similar variability in the distribution of isorientation domains is seen in our multiple electrode penetrations, as described in earlier studies (Hubel and Wiesel, 1963). In places they form narrow stripes but elsewhere form larger, more circular domains. We believe that the beaded appearance of deoxyglucose label is derived from the large domains of isorientation seen in the electrophysiological mapping experiments. While the beads have no obvious relationship to the intrinsic horizontal or corticocortical connections, they may be related, in a way that has yet to be determined, to some other feature of cortical functional architecture or connectivity. For example, the afferents to the superficial layers of area 17 from the $C$ laminae of the LGN have a patchy appearance (LeVay and Gilbert, 1976). We speculate that these afferent patches may be in register with the deoxyglucose bead regions.

The functional implications of the horizontal connections depend on which columns are connected by them and on whether their postsynaptic effect is excitatory or inhibitory. The large majority of the longest range connections, mediated by pyramidal cells, are excitatory, with other pyramidal cells as the postsynaptic cells (Gilbert and Wiesel, 1979; Martin and Whitteridge, 1984; McGuire et al., 1985; Kisvarday et al., 1986; Gabbott et al., 1987). The excitatory nature of the connection is supported by cross-correlation studies (Ts'o et al., 1986; Ts'o and Gilbert, 1988). However, a small proportion of the postsynaptic cells may be inhibitory interneurons (as high as $10 \%$ : McGuire et al., 1985), allowing for some inhibitory effects of the connection. Though more restricted in the lateral extent of their axonal fields than pyramidal cells, large basket cells, which also have clustered axon collaterals, might play a role in these inhibitory processes (Martin et al., 1983). When presenting evidence for interactions between columns of opposite specificity, Matsubara et al. suggested that they could play a role in inhibitory interactions between columns of opposite orientation, also known as "cross-orientation inhibition," though some studies on this subject suggest inhibition from a wider range of orientations than those capable of activating a cell, rather than preferential inhibition from the opposite orientation (Blakemore

\footnotetext{
gradely filled bead-labeled cells in same region as shown in $A$, after injection of beads into a vertical orientation column in area 18 . The region of bead label extended $6 \mathrm{~mm}$ along its long axis, which is roughly parallel to the anteroposterior cortical axis. The cortical axes are indicated at the upper left. $C$, Superimposition of $A$ and $B$. Some of the dots in $C$ are enlarged to make the cell positions easier to see against the background. Scale bar, $1 \mathrm{~mm}$.
} 

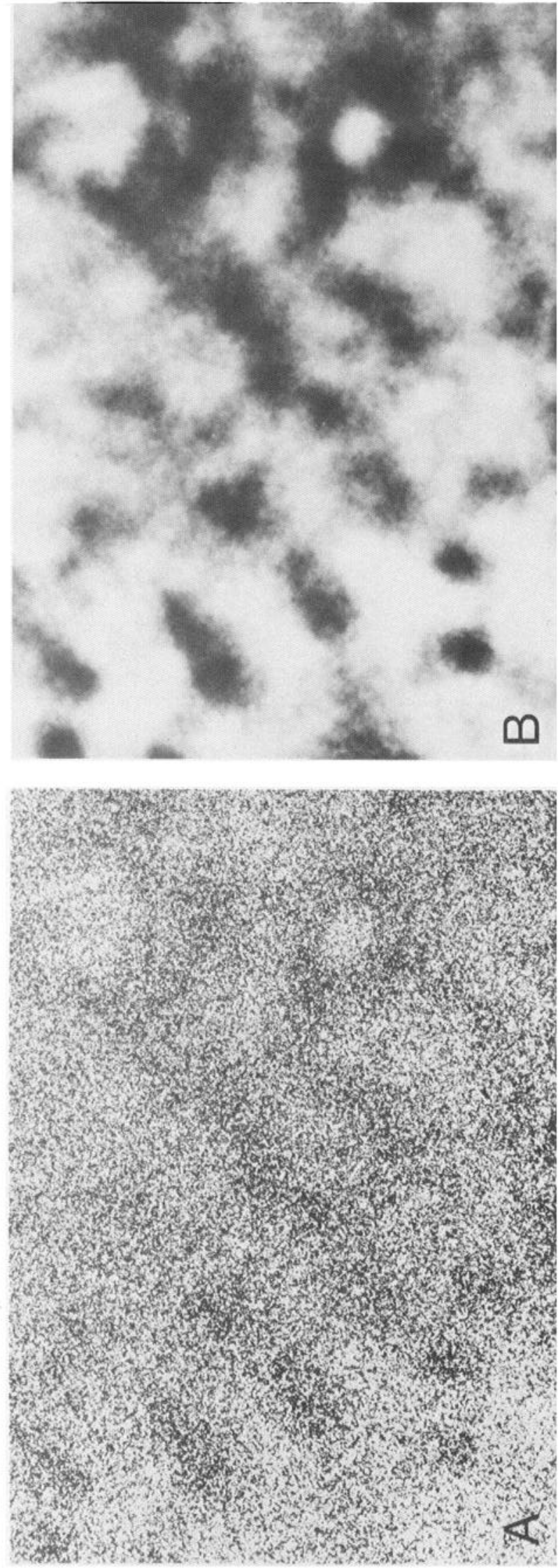

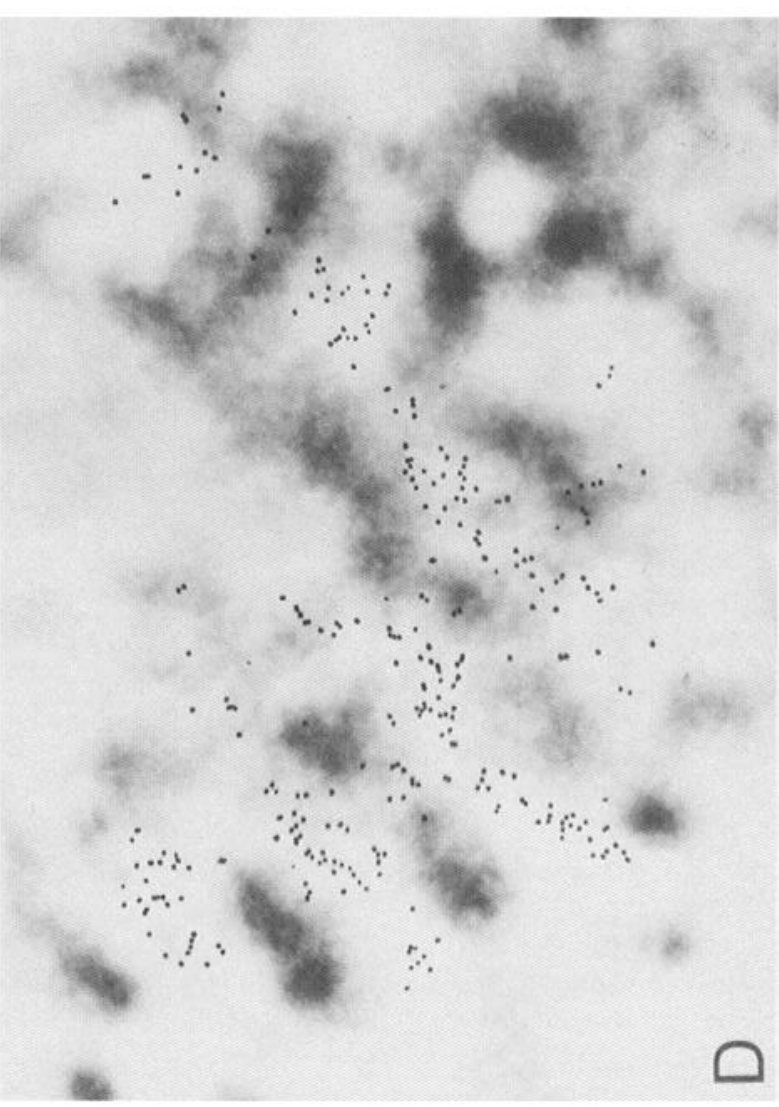

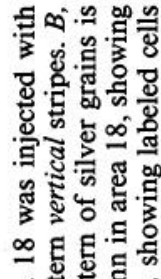

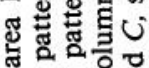

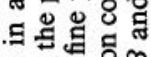

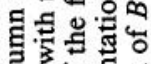

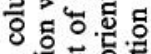

들

ज

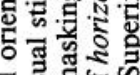

जु.

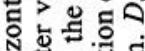

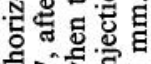

สํ.

击

.

I of 내유

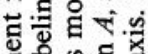

ह 1 .

앵

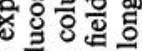

등

추ㅇㅝㅛ

웡면

동

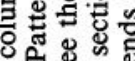

足

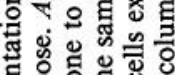

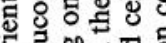

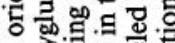

ช

\% 풍

곤

o $\frac{\pi}{3}$.

क옝

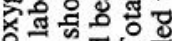

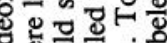

- 政造

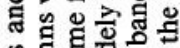

zํㅗㅇ

응

동ㅎㅇ원 댕

경

$\therefore \ldots+\cdots$

홍

ब․

$\therefore$

$\because$ 
and Tobin, 1972; Sillito, 1979; Morrone et al., 1982; Ramoa et al., 1986). Intracellular recording, however, does not support the idea that cortical cells receive either cross-orientation inhibition or inhibition that is more broadly tuned than excitation (Ferster, 1987). Other inhibitory components of a cell's receptive field, such as end inhibition, side-band inhibition and inhibition distant from the receptive field center have been shown to have the same orientation preference as the excitatory portion of the receptive field (Hubel and Wiesel, 1965; Nelson and Frost, 1978; Ferster, 1981), though side-band inhibition was originally reported to be lacking in orientation selectivity (Bishop et al., 1973).

The weight of evidence, however, requires us to consider possible excitatory functional roles for the long-range horizontal connections. This is made difficult in view of the extent of thesc connections, which allows an individual cell to integrate information over a large cortical area. In area 17, the degree of convergence is considerable, up to $8 \mathrm{~mm}$ from end to end. Another useful way of quantifying the extent of the horizontal connections is in terms of numbers of hypercolumns-a full cycle of orientation or ocular dominance columns (Hubel and Wiesel, 1974). The hypercolumn in cat striate cortex is roughly $1 \mathrm{~mm}$. At 2 sites separated by a distance of 2 hypercolumns, the receptive fields of cells, taking into account receptive field size and scatter in receptive field position, are nonoverlapping. Thus, the horizontal connections serve to relate cells with receptive fields separated by many receptive field diameters. The degree of integration of visual information implied by the horizontal connections is therefore difficult to reconcile with established concepts of retinotopic order and receptive field size. The arca of cortical labeling after a single bead injection at a $5^{\circ}$ visual field eccentricity corresponds to a $10^{\circ}$ visual field area. In comparison, the receptive fields of superficial layer cells in this region (with the receptive field defined by conventional stimuli, such as a single light bar or line) are only $1 / 2^{\circ}-2^{\circ}$ across (Hubel and Wiesel, 1962; Gilbert, 1977). Thus, individual cells potentially integrate information over an area of visual field that is an order of magnitude larger than their excitatory response fields.

The labeling of a cell's axonal field, and the distribution of labeled cells after an extracellular injection, does not extend in equal distances at all directions from the injection site. Rather, the labeling is anisotropic, generally extending for longer distances along one cortical axis than along the orthogonal axis. This anisotropy is even more apparent in the projection pattern of individual cells, which tend to have long and narrow axonal fields (Gilbert and Wiesel, 1983). The degree of anisotropy in the projection of single cells strongly suggests that the visuotopic representation of the projection extends along a particular visuotopic axis, rather than being due to anisotropies in magnification factor within the cortex (Hubel and Wiesel, 1977; Tootell et al., 1988). This is further supported by the fact that the long axes of pyramidal cell axonal fields extend along different cortical axes (Gilbert and Wiesel, 1983). Therefore, anisotropic axonal field projections are likely to correspond to preferential projections along a particular visual field axis. Many of the injections that we have made result in labeling that seems to extend for longer distances perpendicular to the orientation axis of the labeled cells than along their orientation axis. We currently have insufficient data to determine if this is a consistent rule.

The evidence on the extent of the horizontal connections when mapped onto the visual field and on their possible excitatory nature has certain implication for their functional role. They may be inadequate to bring a cell above threshold, which would explain why a cell's receptive field can be smaller than the visuotopic area over which it receives input, but they could modulate the response of cells to stimuli that lie within the receptive field. The receptive field, as defined by simple stimuli, represents the local region that the cell analyzes directly. This local analysis could, with the help of the horizontal connections, be communicated over a much wider area, providing the recipient cells with information about the visual context. Thus, context could alter the response properties of the cell with respect to the local features. Influences of this sort have been observed with respect to the sensitivity for differential movement between foreground and background and color constancy (Zeki, 1983; Allman et al., 1985; Tanaka et al., 1986; Orban et al., 1987). In somc instances in V1 the horizontal connections allow for the convergence necessary for building up larger receptive fields, as seen in the projection from layer 5 to layer 6 (Gilbert and Wiesel, 1979; Bolz and Gilbert, 1989) and in the projection from the superficial layers to layer 5 , but in dealing with connections from one superficial layer cell to another located $6 \mathrm{~mm}$ away, there must be another explanation: The extent of the connections is far greater than what one would expect from the cortical representation of the response fields of superficial layer cells.

The clustered nature of projections from one cortical area to another was first observed by HRP injections in one visual cortical area followed by retrograde transport to the antecedent area (Gilbert and Kelly, 1975) and has since been observed in many other cortical regions, including auditory, somatosensory, and frontal cortex (Goldman and Nauta, 1977; Imig and Brugge, 1978; Jones et al., 1978). Based on their anatomical appearance, and on their columnar specificity demonstrated in this and in earlier studies, it appears that the intrinsic and corticocortical connections represent a common mechanism and follow similar rules. In areas 17 and 18 , the convergence provided by the horizontal intrinsic connections may generate subthreshold, contextual influences, and the corticocortical connections may produce larger activating regions. The picture that emerges is a series of cascading and highly convergent connections, with extensive lateral spread within a particular area, convergence in the projection from that area to the next, another series of lateral connections in the second area, and so on down the line. The functional properties generated by the horizontal connections in any given area are likely to be based on the columnar specificity of these connections for that area.

\section{References}

Allman, J. M., F. Miezin, and E. McGuinnes (1985) Direction and velocity specific surround in three cortical visual areas of the owl monkey. Perception 14: 105-126.

Bishop, P. O., J. S. Coombs, and G. H. Henry (1973) Receptive fields of simple cells in the cat striate cortex. J. Physiol. (Lond.) 231: 3160.

Blakemore, C., and E. A. Tobin (1972) Lateral inhibition between orientation detectors in the cat's visual cortex. Exp. Brain Res. 15: $439-440$.

Bolz, J., and C. D. Gilbert (1989) The role of horizontal connections in generating long receptive fields in cat visual cortex. Eur. J. Neurosci. (in press).

Bullier, J., H. Kennedy, and W. Salinger (1984) Branching and laminar origin of projections between visual cortical areas in the cat. J. Comp. Neurol. 228: 329-341.

Ferrer, J. M. R., D. J. Price, and C. Blakemore (1988) The organization of corticocortical projections from area 17 to area 18 of the cat's visual cortex. Proc. R. Soc. London [Biol.] 233: 77-98. 
Ferster, D. (1981) A comparison of binocular depth mechanisms in areas 17 and 18 of the cat visual cortex. J. Physiol. (Lond.) 311:623655.

Ferster, D. (1987) Origin of orientation-selective EPSPs in simple cells of cat visual cortex. J. Neurosci. 7: 1780-1791.

Fisken, R. A., L. J. Garey, and T. P. S. Powell (1975) The intrinsic, association and commissural connections of area 17 of the visual cortex. Phil. Trans. R. Soc. Lond. [Biol.] 272: 487-536.

Gabbott, P. L. A., K. A. C. Martin, and D. Whitteridge (1987) Connections between pyramidal neurons in layer 5 of cat visual cortex (area 17). J. Comp. Neurol. 259: 364-381.

Gilbert, C. D. (1977) Laminar differences in receptive field properties in cat primary visual cortex. J. Physiol. (Lond.) 268: 391-421.

Gilbert, C. D., and J. P. Kelly (1975) The projections of cells in different layers of the cat's visual cortex. J. Comp. Neurol. 163: 81106.

Gilbert, C. D., and T. N. Wiesel (1979) Morphology and intracortical projections of functionally identified neurons in cat visual cortex. Nature 280: 120-125.

Gilbert, C. D., and T. N. Wiesel (1981a) Projection bands in visual cortex. Soc. Neurosci. Abstr. $7: 356$.

Gilbert, C. D., and T. N. Wiesel (1981b) Laminar specialization and intracortical connections in cat primary visual cortex. In The Organization of the Cerebral Cortex, F. O. Schmitt, F. J. G. Worden, G. Adelman, and S. G. Dennies, eds., pp. 163-194, MIT, Cambridge, MA.

Gilbert, C. D., and T. N. Wiesel (1983) Clustered intrinsic connections in cat visual cortex. J. Neurosci. 3: 1116-1133.

Goldman, P. S., and W. J. H. Nauta (1977) Columnar distribution of cortico-cortical fibers in the frontal association, limbic and motor cortex of the developing rhesus monkey. Brain Res. 122: 393-413.

Goldman-Rakic, P. S., and M. L. Schwartz (1982) Interdigitation of contralateral and ipsilateral columnar projections to frontal association cortex in primates. Science 216: 755-757.

Hubel, D. H., and T. N. Wiesel (1962) Receptive fields, binocular interaction and functional architecture in the cat's visual cortex. J. Physiol. (Lond.) 160: 106-154.

Hubel, D. H., and T. N. Wiesel (1963) Shape and arrangement of columns in cat's striate cortex. J. Physiol. (Lond.) 165: 559-568.

Hubel, D. H., and T. N. Wiesel (1965) Receptive fields and functional architecture in two nonstriate visual areas (18 and 19) of the cat. J. Neurophysiol. 38: 229-289.

Hubel, D. H., and T. N. Wiesel (1974) Uniformity of monkey striate cortex: A parallel relationship between field size, scatter and magnification factor. J. Comp. Neurol. 158: 295-306.

Hubel, D. H., and T. N. Wiesel (1977) Functional architecture of macaque monkey visual cortex. Proc. R. Soc. London [Biol.] 198: 159.

Imig, T. J., and J. F. Brugge (1978) Sources and terminations of callosal axons related to binaural and frequency maps in primary auditory cortex of the cat. J. Comp. Neurol. 182: 637-660.

Imig, T. J., and R. A. Reale (1981) Ipsilateral corticocortical projections related to binaural columns in cat primary auditory cortex. J. Comp. Neurol. 203: 1-14.

Jones, E. G., J. D. Coulter, and S. H. C. Hendry (1978) Intracortical connectivity of architectonic fields in the somatic sensory, motor and parietal cortex of monkeys. J. Comp. Neurol. 181: 291-348.

Katz, L. C., A. Burkhalter, and W. J. Dreyer (1984) Fluorescent latex microspheres as a retrograde neuronal marker for in vivo and in vitro studies of visual cortex. Nature 310:498-500.

Kisvarday, Z. F., K. A. C. Martin, T. F. Freund, Z. Magloczky, D. Whitteridge, and P. Somogyi (1986) Synaptic targets of HRP-filled layer III pyramidal cells in the cat striate cortex. Exp. Brain Res. 64: 541-552.

LeVay, S., and C. D. Gilbert (1976) Laminar patterns of geniculocortical projection in the cat. Brain Res. 113: 1-19.

Livingstone, M. S., and D. H. Hubel (1984a) Anatomy and physiology of a color system in the primate visual cortex. J. Neurosci. 4: 309366 .

Livingstone, M. S., and D. H. Hubel (1984b) Specificity of intrinsic connections in primate primary visual cortex. J. Neurosci. $4: 2830$ 2835.

Lorente de No, R. (1949) Cerebral cortex: Architecture, intracortical connections, motor projections. In Physiology of the Nervous System. 3rd ed., J. F. Fulton, ed., pp. 288-313, Oxford U. P., London.
Lowell, S., B. Freeman, and W. Singer (1987) Topographic organization of the orientation column system in large flat-mounts of the cat visual cortex: A 2-deoxyglucose study. J. Comp. Neurol. 255: $401-415$.

Lund, J. S., and R. G. Boothe (1975) Interlaminar connections and pyramidal neuron organization in the visual cortex, area 17, of the Macaque monkey. J. Comp. Neurol. 159: 305-334.

Martin, K. A. C., and D. Whitteridge (1984) Form, function and intracortical projections of spiny neurones in the striate visual cortex of the cat. J. Physiol. (Lond.) 353: 463-504.

Martin, K. A. C., P. Somogyi, and D. Whitteridge (1983) Physiological and morphological properties of identified basket cells in the cat's visual cortex. Exp. Brain Res. 50: 193-200.

Matsubara, J. A., M. S. Cynader, and N. V. Swindale (1987) Anatomical properties and physiological correlates of the intrinsic connections in cat area 18. J. Neurosci. 7: 1428-1446.

Maunsell, J. H. R., and D. C. Van Essen (1983) The connections of the middle temporal visual area (MT) and their relationship to a cortical hierarchy in the macaque monkey. J. Neurosci. 3: 2563-2586.

McGuire, B. A., C. D. Gilbert, and T. N. Wiesel (1985) Ultrastructural characterization of long-range horizontal connections in monkey striate cortex. Soc. Neurosci. Abstr. 11: 17.

Mitchison, G., and F. Crick (1982) Long axons within the striate cortex: Their distribution, orientation, and patterns of connection. Proc. Natl. Acad. Sci. USA 79: 3661-3665.

Montero, V. M. (1980) Patterns of connections from the striate cortex to cortical visual areas in superior temporal sulcus of macaque and middle temporal gyrus of owl monkey. J. Comp. Neurol. 189: 4559.

Morrone, M. C., D. C. Burr, and L. Maffei (1982) Functional implications of cross-orientation inhibition of cortical visual cells. I. Neurophysiological evidence. Proc. R. Soc. London [Biol.] 216: 335-354.

Nelson, J. I., and B. Frost (1978) Orientation selective inhibition from beyond the classic visual receptive field. Brain Res. 139: 359-365.

Olavarria, J., and C. Van Sluyters (1985) Unfolding and flattening the cortex of gyrencephalic brains. J. Neurosci. Methods 15: 191-202.

O'Leary, J. L. (1941) Structure of the area striata of the cat. J. Comp. Neurol. 75: 131-161.

Orban, G. A., B. Gulyas, and R. Vogels (1987) Influence of a moving textured background on direction selectivity of cat striate neurons. $J$. Neurophysiol. 57: 1792-1812.

Ramoa, A. S., M. Shadlen, B. C. Skottun, and R. D. Freeman (1986) A comparison of inhibition in orientation and spatial frequency selectivity of cat visual cortex. Nature 321: 237-239.

Ramón y Cajal, S. (1922) Studien uber die Sehrinde der Katze. J. Psychol. Neurol. 29: 161-181

Rockland, K. S., and J. S. Lund (1982) Widespread periodic intrinsic connections in the tree shrew visual cortex. Brain Res. 169: 19-40.

Rockland, K. S., and J. S. Lund (1983) Intrinsic laminar lattice connections in primate visual cortex. J. Comp. Neurol. 216: 303-318.

Schoppmann, A., and M. P. Stryker (1981) Physiological evidence that the 2-deoxyglucose method reveals orientation columns in cat visual cortex. Nature 293: 574-576.

Sillito, A. (1979) Inhibitory mechanisms influencing complex cell orientation selectivity and their modification at high resting discharge. J. Physiol. (Lond.) 250: 305-329.

Tanaka, K., K. Hikosaka, H. Saito, M. Yukie, Y. Fukada, and E. Iwai (1986) Analysis of local and wide-field movements in the superior temporal visual areas of the macaque monkey. J. Neurosci. 6: 134144.

Tigges, J., M. Tigges, S. Anschel, N. A. Cross, W. D. Letbetter, and R. L. McBride (1981) Areal and laminar distribution of neurons interconnecting the central visual cortical areas 17, 18,19 and MT in Squirrel monkey (Saimiri). J. Comp. Neurol. 202: 539-560.

Tootell, R. B. H., and M. S. Silverman (1985) Two methods for flatmounting cortical tissue. J. Neurosci. Methods 15: 177-190.

Tootell, R. B. H., E. Switkes, M. Silverman, and S. L. Hamilton (1988) Functional anatomy of Macaque striate cortex. II. Retinotopic organization. J. Neurosci. 8: 1531-1568.

Ts'o, D., and C. Gilbert (1988) The organization of chromatic and spatial interactions in the primate striate cortex. J. Neurosci. $8: 1712$ 1727.

Ts'o, D., C. Gilbert, and T. N. Wiesel (1986) Relationships between horizontal connections and functional architecture in cat striate cortex as revealed by cross-correlation analysis. J. Neurosci. 6: 1160-1170. 
Ts'o, D., C. Gilbert, and T. N. Wiesel (1987) Organization and connectivity of color-specific cells in cytochrome oxidase-rich patches of monkey striate cortex. Soc. Neurosci. Abstr. 13: 2.

Tusa, R. J., L. A. Palmer, and A. C. Rosenquist (1978) The retinotopic organization of area 17 (striate cortex) in the cat. J. Comp. Neurol. 177: 213-236.
Wong-Riley, M. (1979) Columnar cortico-cortical interconnections within the visual system of the squirrel and macaque monkeys. Brain Res. 162: 201-217.

Zeki, S. M. (1983) Colour coding in the cerebral cortex: The reaction of cells in monkey visual cortex to wavelengths and colours. Neuroscience 9: 741-765. 